\title{
Linking Experiences and Outcomes within a Postsecondary Leadership Development Program
}

\author{
Kellie Strawn \\ Corvallis, OR 97331 \\ Aaron J. McKim \\ Assistant Professor, Michigan State University \\ East Lansing, MI 48824 \\ Jonathan J. Velez \\ Associate Professor, Oregon State University \\ Corvallis, OR 97331
}

\begin{abstract}
This qualitative study explored the leadership development outcomes associated with specific experiences in a one-year, intensive leadership development program at a large northwest research university. Students highlighted three programmatic experiences for their effectiveness: (a) faculty mentoring, (b) participation in a weekly seminar, and (c) experiential learning through sustained community involvement. As students discussed these experiences, they identified building relationships, gaining a deeper understanding of leadership, exposure to new experiences, and increased communication skills as outcomes associated with having a mentor. When discussing the interactive seminars, students articulated collective growth, increased self-awareness, improved reflection skills, and a deeper understanding of leadership as outcomes of seminar participation. For the experiential learning component, students identified outcomes associated with being pushed out of their comfort zones, improving networking skills, awareness of the value of community involvement, and relationship skill building. Conclusions and recommendations are discussed for the application of these experiences in leadership education.
\end{abstract}

\section{Introduction}

"I'm really thankful for the Leadership Academy experience, because it helped me grow as a person. It pushed me down a path that I wanted to go on but didn't think I was capable of going down, and the people I met along the way really helped me through it, and I'm extremely thankful for their help and their guidance." - Jane, 2013 Leadership Academy graduate

Twelve months earlier, Jane sat in an interview room after having submitted a paper application to an undergraduate leadership development program and answering questions about her desire to learn and grow and her ability to take feedback and try new things. She was not polished, but she recognized her own weaknesses and need for further development. A committee of several faculty members selected Jane and ten other undergraduate students to participate in the program. As the program administrators, we paired Jane with a faculty 
member, who would serve as her mentor, and we did the same for every other student in the program. Through common experiences, candid discussions, and time together in a weekly seminar, the group became a cohort.

Jane created a roadmap for herself, setting leadership development goals, which she could tackle during her year in the program. She aligned the requirements of the program with her goals, to more purposefully engage in leadership development. Jane attended workshops and a weekly seminar, where she learned new skills and leadership perspectives. Then she got involved with a student club, volunteered for a community organization, and attended professional networking events to practice those skills. Jane's mentor provided guidance, encouragement, and advice each step of the way, helping Jane debrief and reflect on her experiences.

Jane had confidence that the skills she worked to develop mattered, because she interacted regularly with industry professionals, some of whom served as advisers to the program, ensuring the curriculum and requirements were relevant and valuable for students who would soon enter the workforce. Research in leadership education has also identified many of these skills - problem solving, teamwork, communication, decision making, organization of information, writing, critical thinking, and many others - as essential for college graduates (APLU, 2009; NFAMEC, 2006; SCANS, 2000).

The National Food and Agribusiness Management Education Commission (NFAMEC, 2006) identified interpersonal communication, critical thinking, and writing "among the most important skills that industry desires in new hires with the capacity to become leaders" (p.5). Likewise, the Association of Public and Land Grant Universities (APLU, 2009) compiled the responses of employers, alumni, faculty, and students, ranking communication, decision making, self-management, teamwork, professionalism, experience, and leadership, in that order, as important skills for new graduates. Using the 1991 Secretary's Commission on Achieving Necessary Skills (SCANS) as a framework, and commissioned by the U.S. Department of Labor Employment and Training Administration, ACT, Inc. (2000) described a number of essential workplace skills, including integrity and honesty, acquiring and evaluating information, exercising leadership, participating as a team member, creative thinking, decision making, and listening.

Undergraduate students recognize some of these needs and have articulated a preference for personal growth and skill-building activities, self-development opportunities, and personalized settings, when pursuing leadership development (Allen \& Hartman, 2009). Allen and Hartman recommended using "a variety of learning interventions" to positively affect the greatest number of students, despite differences in learning styles (p. 15). Leadership educators do employ a number of instructional strategies in the classroom (Jenkins, 2012), but little research exists that describes the outcomes specific to those instructional strategies. So we asked the question, what learning outcomes do graduates of this yearlong leadership program identify as a result of having completed the program? Based on this question we sought to explore the potential connections between students' experiences in a leadership development program and the outcomes they articulate 


\section{Literature Review}

Existing literature has shown leadership is a skill, one that educational experiences can develop (Bennis, 1994; Buschlen \& Dvorak, 2011; Wimmer, Meyers, Porter, \& Shaw, 2012). Furthermore, many have identified the college experience as an ideal time to focus on leadership development (Astin \& Astin, 2000; Buschlen \& Dvorak, 2011; Komives, Owen, Longerbeam, Mainella, \& Osteen, 2005). Not surprisingly, the number of collegiate leadership development programs has been on the rise (Dugan \& Komives, 2007; Engbers, 2006), which has created a need to identify the leadership skills developed through these college experiences.

Student involvement in collegiate leadership development programs has been found to increase leadership skills (Cress, Astin, Zimmerman-Oster, \& Burkhardt, 2001). Dugan and Komives (2007) found student involvement in long-term, formal leadership development programs, of which the program studied is one, significantly enhanced the outcomes of creating change, citizenship, collaboration, and establishing a common purpose. In a more recent study, Buschlen and Dvorak (2011) found a college leadership experience, using the social change model, effectively enhanced consciousness of self, group values, and community values among students.

These studies provide evidence that experiences within collegiate leadership development programs and classrooms yield positive leadership outcomes, yet they fail to provide a clear description of student involvement in these experiences. A number of studies have addressed the experiences within leadership development programs, including a 2009 study by Allen and Hartman. Allen and Hartman categorized leadership development activities using a model originally proposed by Conger (1992) which identified leadership development occurring through four types of experiences: (a) personal growth, (b) conceptual understanding, (d) feedback, and (e) skill building. Within each of these four types of experiences, researchers identified a variety of experiences which occur in leadership development programs, for example service learning activities (i.e. personal growth), reading leadership texts (i.e. conceptual understanding), self-assessments of leadership (i.e. feedback), and role-playing activities (i.e. skill building).

Jenkins (2012) expanded on the work of Allen and Hartman to identify the most commonly used experiences within leadership education. This study identified class discussions, interactive lectures, small group discussions, group projects, and research projects as the most commonly used pedagogies in leadership education. The next logical step in the research process is to identify the links between specific curricular experiences and leadership skill development. Yet, research has identified that one of the key challenges among the leadership education community is the process of linking program activities with intended outcomes and impact (Russon \& Reinelt, 2004).

Dugan and Komives (2007) attempted to link specific experiences with leadership outcomes. Researchers were able to identify that mentoring, campus involvement, community service, leadership roles, and formal leadership development programs positively influenced students' leadership development. Yet, this study did not explore students' level or type of involvement in these experiences. Our study used the theory of student involvement (Astin, 
1970a, 1970b, 1991, 1999), which identified the need to understand both the level and type of student involvement, to explore students' reflections of experiences while involved in a yearlong leadership development program and the outcomes they articulate while talking about those experiences. Through this analysis, we sought to provide evidence of potential connections between specific leadership development experiences and specific leadership development outcomes.

\section{Theoretical Framework}

We used the theory of student involvement (Astin, 1970a, 1970b, 1991, 1999) to interpret and discuss the findings of our research. The theory of student involvement seeks to explain student development though college experiences by using three components: (a) inputs, (b) environment, and (c) outcomes, in a model typically called the I-E-O model. Inputs refer to the characteristics and experiences with which students enter into their college experience, including demographic variables and background. The second variable in this model is the college environment. Astin identified both distal and proximal aspects of this environment. The distal aspect accounts for the climate of the institution as a whole. Variables such as school size, types of buildings, and location of school are important when considering the distal aspects of the college environment. Proximal aspects, the environmental variables considered in this study, include variables in which the students are immersed while in college. Proximal aspects include classroom discussions, level of involvement on campus, and leadership training experiences like the one of interest in this analysis.

The final component of the I-E-O model is outcomes of student experiences. These outcomes encompass the characteristics, skills, knowledge, attitudes, beliefs, and values students exhibit as they finish their college experience. We sought to identify potential links between the experiences of students involved in a leadership development program and the outcomes they described from that involvement.

\section{Methods}

The purpose of this qualitative study was to explore potential connections between the experiences of students in a leadership development program and the outcomes they articulated. Like past studies in leadership education with similar objectives (e.g. Odom, 2015), we chose to study these potential connections using a qualitative research method.

Data Collection. We collected data from all eleven participants in the leadership development program. Data were collected a week after completion of the program, through a one-on-one, semi-structured, audio-recorded interview (Creswell, 2009). Each interview lasted between 30 and 45 minutes. Building on the work of Odom (2015), we elicited respondents' reflections of experiences in the program by asking, for example "What benefits and challenges did you experience through the weekly seminars?" and "What did you learn through interaction with your mentor?" Follow-up questions helped us identify additional information about students' experiences in the leadership development program. 
Data Analysis. The data analysis process utilized showcases the "ongoing process involving continual reflection about the data" (Creswell, 2009, p. 184). We began the process by first preparing the data for analysis by transcribing the interviews. We then read through the transcripts to identify general concepts in the data. We met and discussed our initial interpretation of the data, which involved coding for learning outcomes identified by students. After initial analysis, a number of outcomes-based themes emerged. We reexamined the data to determine if students identified those outcomes when discussing specific experiences in the leadership development program and coded the data by identifying outcomes students articulated as they talked about certain aspects of the program. For example, when we asked one student, "what did you learn through interaction with your mentor?" he indicated, "I learned the value of building rapport with someone." We coded the outcome of this comment as learning the value of building rapport and the experience as the mentoring component of the program. During this round of analysis, three program-component themes emerged: (a) mentoring, (b) seminars, and (c) experiential learning. Although these were not the only aspects of the program, respondents referenced these experiences numerous times in the data; therefore, these programmatic elements are the focus of our findings. We then came to a consensus on our codes connecting the program component themes and outcome themes, which we will refer to as main themes and subthemes, respectively.

Participants. The participants in this study included eleven students in either the College of Agricultural Sciences or the College of Forestry at Oregon State University. The participants included six females and five males. Students ranged from sophomore status to senior status. To keep the identities of the students confidential, we have replaced students' names with pseudonyms for our description.

Research Quality. Throughout this study we sought to increase the reliability and validity of our findings. We sought to increase the reliability by continually meeting as a research team to discuss our interpretations of the data and cross-check our codes (Creswell, 2009). We sought to increase the validity of our findings by using three researchers to triangulate the data analysis and coding process and by using rich descriptions and student quotes to describe the findings (Creswell, 2009).

Limitations. An additional method for increasing the validity of our findings is being open about our experiences and involvement in the program that may have led to biases in our interpretation of the data. We all worked very closely with the leadership development program we are studying. Our involvement in this program included facilitating seminars, organizing the experiences associated with the program, and meeting with students throughout the year to encourage their success as they participate in the program. Through the use of continual meetings, cross-checking of codes, triangulation of data analysis and rich descriptions of the data, we attempted to overcome our potential biases and believe the findings presented through this study are valuable to the leadership education profession.

An additional limitation of qualitative research is the lack of generalizability of the findings (Creswell, 2009). Qualitative research is best suited for exploring, in more depth, the experiences and interpretations of a small number of people. We acknowledge this limitation, and make no attempt to generalize our findings beyond the participants in this research study. 


\section{Findings}

Analysis of the participant responses revealed several clear themes relating to programmatic elements and several subthemes related to program outcomes. We use tables to highlight the student results pertaining to three programmatic aspects of the program. While some of the subthemes differ, it is important to recognize that some similar subthemes emerged while students discussed different experiences. The student quotes attributed to subthemes were provided in the context of the specified main themes (i.e. mentoring, seminars, and experiential learning).

Mentoring. Each participant interacted with one faculty mentor for the duration of the academic year. Typically, students met once or twice per month for one-hour mentoring sessions. The mentoring relationship was open-ended and, with the exception of a short, mentor orientation, mentors were free to individualize their approach to mentoring. Review of the data revealed several subthemes (i.e. leadership development outcomes from being mentored) that emerged when asking students about their experiences working with a faculty mentor. Subthemes included growth in relationships, improved ability to understand leadership, the new experience of mentoring, and development of communication skills. Table one highlights some of the student data associated with each of these subthemes. 
Table 1.

Leadership Development Subthemes from Being Mentored

\begin{tabular}{|c|c|}
\hline $\begin{array}{l}\text { Mentoring } \\
\text { Subthemes }\end{array}$ & Participant Quotations \\
\hline \multirow[t]{5}{*}{ Relationships } & $\begin{array}{l}\text { "She taught me how important it is to be nice to people and be friends with } \\
\text { people and build a relationship with them" (Jane) }\end{array}$ \\
\hline & $\begin{array}{l}\text { "He opened my eyes to the value of listening and conversation skills and } \\
\text { building relationships" (Trevor) }\end{array}$ \\
\hline & $\begin{array}{l}\text { "Another great thing about it was learning about the mentoring relationship } \\
\text { and the value of it" (Trevor) }\end{array}$ \\
\hline & $\begin{array}{l}\text { "I just learned the value of building rapport with someone and taking the } \\
\text { time to sit down and really talking things through with them" (Ruth) }\end{array}$ \\
\hline & $\begin{array}{l}\text { "I really appreciated knowing that there was someone in the college who I } \\
\text { could go to if I had any questions, sit over a cup of coffee with and just } \\
\text { hash out life with" (Ruth) }\end{array}$ \\
\hline \multirow[t]{3}{*}{$\begin{array}{l}\text { Understanding } \\
\text { Leadership }\end{array}$} & $\begin{array}{l}\text { "I would say that I learned a lot about myself as well as how to be an } \\
\text { effective and well-rounded leader" (Lacy) }\end{array}$ \\
\hline & $\begin{array}{l}\text { "I learned from him that to be a leader is to stand up for what is right and } \\
\text { also have a core set of values to go back to" (Neil) }\end{array}$ \\
\hline & $\begin{array}{l}\text { "...hearing how he learned these skills and how he struggled with them } \\
\text { and what he's done to overcome those were really, really great } \\
\text { conversations" (Trevor) }\end{array}$ \\
\hline \multirow[t]{2}{*}{ New Experience } & $\begin{array}{l}\text { "I think having a mentor is key because looking back, trying to do this all } \\
\text { on my own, I never would have done it" (Lacy) }\end{array}$ \\
\hline & $\begin{array}{l}\text { "it was my first interaction with somebody in like a faculty position that } \\
\text { wasn't one of my professors" (Andrew) }\end{array}$ \\
\hline \multirow[t]{3}{*}{ Communication } & $\begin{array}{l}\text { "He really encouraged me to look at conversation, to really work on } \\
\text { interpersonal communication with others"(Jill) }\end{array}$ \\
\hline & $\begin{array}{l}\text { "I really learned a lot about effective communication with colleagues, } \\
\text { things that work and don't work" (Henry) }\end{array}$ \\
\hline & $\begin{array}{l}\text { "We worked a lot on communication and not just like communication like } \\
\text { how do I structure this; it was more so okay how do I effectively connect } \\
\text { with you inside of a professional relationship" (Brittany) }\end{array}$ \\
\hline
\end{tabular}

Seminar. Students participated in a yearlong seminar course, which we facilitated. The course met for two hours, weekly, for the entire academic year. When the participants referenced the seminars in the data, four prevalent themes emerged: (a) collective growth, (b) selfawareness, (c) reflection skills, and (d) understanding leadership. Table two provides an 
overview of the student findings related to these four themes.

Table 2.

Leadership Development Subthemes from Participation in Seminars

\section{Seminar}

Subthemes

Collective

Growth

Self-Awareness

Reflection Skills

Understanding

Leadership

\section{Participant Quotations}

“...the benefit was just being able to have a group. It was almost like a sounding board" (Jane)

"...getting to interact with the rest of the cohort and learn from them was a huge benefit" (Trevor)

“...really discussing about leadership stuff because when you're just reading a book or, you know, learning it by yourself, you're not really getting that feedback that you need" (Jill)

"There are some really amazing leaders in that class and in the Leadership Academy, and it's just great to feed off of one another, get each other's input and insights and kind of just grow together" (Ruth)

“.... and the biggest thing I gained out of that [seminar] was the tools to use for listening" (David)

“...the emotions [seminar], I really caught myself when I was trying to talk somebody through an issue that I might have been having with them" (Henry)

"I thought it was really good to have those seminars to get feedback, to learn a lot more, to be able to apply it to like exercises, and challenge yourself, see where you are" (Jill)

"I've only had a couple classes that I've really left like really thinking a lot about after and those are the ones you really remember" (Andrew)

“...so the leadership seminars were incredible, probably my favorite part of the entire process" (Brittany)

"...is really beneficial just to sit down and listen to and just kind of learn" (Ruth)

"I'm going to use this idea and I'm going to implement it and work on it so that was a strength" (David)

"Additionally the agenda workshop has made my meetings, both officer and chapter, of different clubs run much smoother, much more clarity, things get done, the action is there now" (Henry) 
Experiential Learning. In the program, we asked students to volunteer and engage with an off-campus community organization for approximately four hours per week for the academic year. The impact of the experiential learning experience was evident in the lives of students and the subthemes of being pushed, networking, community involvement, and relationship skills emerged. Table three highlights the subthemes associated with their experiential learning.

Table 3.

Leadership Development Subthemes from Participation in Experiential Learning

\section{Experiential \\ Learning \\ Subthemes}

Being Pushed

Participant Quotations

"I mean the challenge kind of turned into a benefit in that I got the experience of utilizing my communication that I've been working on" (Henry)

"I thought it was great to make sure that the cohort is going outside of the college you know as a comfort zone type of thing we tend to stick to what we know, and I absolutely loved it" (Lacy)

"I learned how to work with diversity" (Kim)

"I really appreciated that just little reminder from the Leadership Academy, that what we do is important, and the organizations that we are involved in, they have a purpose and we need to make our time in those important or purposeful and effective" (Ruth)

Networking

“...now my network, if you will, has expanded even more and I have gotten a lot out of that" (Jane)

"I got the opportunity to meet a lot of really interesting people" (Andrew)

"One of the benefits was meeting new people, creating new friendships, networking" (Kim)

Community “...it was the first time I'd really done some really good leadership work Involvement like outside of the community or outside the university" (Jill)

"I interacted a lot with the people of Corvallis and learned a lot about this town, the people in it and it was a really great experience" (Lacy)

"I now understand that community involvement is really important to me" (Brittany)

Relationship Skills "I felt like I was doing something benefiting both me and the residents" (Andrew)

"...working with people that were a lot older than me, basically kind of like a different population" (Jill) 
"I was able to build relationships with people over the term and that was what one of my goals was so that was really beneficial" (Trevor)

\section{Discussion \& Conclusions}

As we began this study, our purpose was to explore the learning outcomes associated with specific programmatic experiences. Prior literature has explored leadership education pedagogies, but we wanted to examine specific programmatic inputs and their relationship to specific student learning outcomes. While our research method prevents us from establishing a causal connection, the results do provide some evidence for the link between programmatic experiences and ultimately student leadership learning. The students themselves provided evidence for learning as they reflected back on their experiences.

Prior studies have shown that leadership development programs increase leadership skills (Cress et al., 2001). However, given the fact that the number of leadership programs is growing, it is imperative to begin the process of examining the pedagogical and programmatic components students are identifying as promoting leadership growth. This study revealed a clear connection between leadership growth and the three programmatic elements of (a) mentoring, (b) a weekly seminar, and (c) experiential learning.

The results revealed being actively engaged with a faculty mentor aided students in their conceptualizations of relationships, understanding of leadership, and communication. Students referenced the mentor relationship as a new experience that was instrumental in promoting their growth. It is encouraging to see the student results considering the faculty mentoring relationships were not highly structured. Faculty members tend to be busy with teaching, research, and service; therefore, it is easier to recruit faculty when the time constraints of mentoring are low. In this case, we only required one two-hour mentor orientation session for faculty to begin this process. We recommend programs consider using faculty in mentoring roles with a practical understanding of their time constraints. This study revealed that with minimal upfront investment, a program where faculty serve as mentors can help to facilitate evidence of student leadership growth.

The development of a yearlong seminar, while presenting a logistical challenge, as it spans multiple semesters/quarters, provided an environment that promoted collective growth, enhanced self-awareness, and facilitated the development of reflection skills as well as an understanding of leadership. Regarding collective growth, students enrolled in this program are part of a cohort. The same students persist in the program for the entire year. This allowed students to develop close relationships, and students referenced this group as a "sounding board," a "huge benefit," and a group where "it's just great to feed off of one another." Future programs should consider the leadership growth that occurs through sustained, facilitated interaction. In addition, students referenced the development of self-awareness and reflection skills, both critical components of leadership. Programmatically, we facilitated the seminar course, and an industry-based advisory board identified the seminar topics. This helped ensure that the content was relevant to industry needs and potentially also aided in student buy-in and engagement 
during the seminars.

When discussing their off-campus, community-based experiential learning, students referenced being pushed, increasing learning and understanding regarding community involvement, networking, and relationship skills as areas of growth. Based on this weekly investment of three to four hours, students grew in their leadership. We recommend administrators of leadership development programs consider implementing off-campus community involvement, if they want to push students and enhance awareness of the importance of being involved in a community. The student voices in this study were very pronounced. Students learned and grew through community involvement.

The findings of this study help to articulate important considerations in the use of the student involvement theory. This study identified three proximal components (i.e. faculty mentoring, interactive leadership seminars, and community involvement) of an environment focused on the development of leadership skills among college students. The data suggest each of these proximal experiences were conducive to the development of a variety of positive leadership outcomes. Leadership educators should consider the implementation of these experiences when designing leadership programs.

In this study, we took the first step down a road that, given further research, will eventually provide the causal links necessary to support the essential programmatic elements of an effective leadership development program, based on the desired learning outcomes. Students are only with us for a while, yet they interact with us during a highly pivotal stage in their growth and development. We owe it to students like Jane to develop programs that help students grow, push their development, exceed their perceived capabilities, enhance their relationships, and provide help and guidance during this transformative stage. Our task is not easy, but the rewards of a changed life compel our efforts.

\section{References}

Allen, S. J., \& Hartman, N. S. (2009). Sources of learning in student leadership development programming. Journal of Leadership Studies, 3(3), 6-16. doi: 10.1002/jls.20119.

Astin, A. W. (1970a). The methodology of research on college impact, part one. Sociologyof Education, 43(3), 223-254. doi: 10.2307/2112065

Astin, A. W. (1970b). The methodology of research on college impact, part two. Sociologyof Education, 43(4), 437-450. doi: 10.2307/2111842

Astin, A. W. (1991). Assessment for excellence. New York, NY: Macmillan.

Astin, A. W. (1999). Student involvement: A developmental theory for higher education. Journal of College Student Development, 40(5), 518-529. 
Astin, A. W., \& Astin, H. S. (2000). Leadership reconsidered: Engaging higher education in social change. Battle Creek, MI: W. K. Kellogg Foundation.

Association of Public and Land-Grant Universities [APLU]. (2009). Human Capacity Development The Road to Global Competitiveness and Leadership in Food, Agriculture, Natural Resources, and Related Sciences (FANRRS).Washington, DC. Retrieved from http://www.aplu.org/NetCommunity/ Document.Doc?id=1639

Bennis, W. (1994). On becoming a leader. Reading, MA: Addison-Wesley.

Buschlen, E., \& Dvorak, R. (2011). The social change model as pedagogy: Examining undergraduate leadership growth. Journal of Leadership Education, 10(2), 38-56. doi: 10.12806/V10/I2/RF2

Conger, J. (1992). Learning to lead: The art of transforming managers into leaders. San Francisco, CA: Jossey-Bass.

Cress, C., Astin, H. S., Zimmerman-Oster, K., \& Burkhardt, J. C. (2001). Developmental outcomes of college students' involvement in leadership activities. Journal of College Student Development, 42(1), 15-26.

Creswell, J. W. (2009). Research design: Qualitative, quantitative, and mixed methods approaches $\left(3^{\text {rd }} \mathrm{ed}\right.$.). SAGE Publications, Incorporated.

Dugan, J. P., \& Komives, S. R. (2007). Developing leadership capacity in college students: Findings from a national study. A Report from the Multi-Institutional Study of Leadership. College Park, MD: National Clearinghouse for Leadership Programs.

Engbers, T. A. (2006). Student leadership programming model revisited. Journal of Leadership Education, 5(3), 1-14. doi: 10.12806/V5/I3/TF1

Jenkins, D. M. (2012). Exploring signature pedagogies in undergraduate leadership education. Journal of Leadership Education, 11(1), 1-27. doi: 10.12806/V11/I1/RF1

Komives, S. R., Owen, J. E., Longerbeam, S. D., Mainella, F. C., \& Osteen, L. (2005). Developing a leadership identity: A grounded theory. Journal of College Student Development, 46(6), 593-611. doi: 10.1353/csd.2005.0061

National Food and Agribusiness Management Education Commission [NFAMEC]. (2006). Food and Agribusiness Management Education: Future Directions. Retrieved from https://www.agecon.purdue.edu/cab/NFAMEC/NFAMEC\%20Final\%20Report.pdf

Odom, S. F. (2015). Undergraduate student perceptions of the pedagogy used in a leadership course: A qualitative examination. Journal of Leadership Education, 14(2), 17-29. doi: 1012806/V14/I2/R2. 
Russon, W., \& Reinelt, C. (2004). The results of an evaluation scan of 55 leadership development programs. Journal of Leadership \& Organizational Studies, 10(3), 104-107. doi: 10.1177/107179190401000309

Secretary's Commission on Achieving Necessary Skills [SCANS]. (2000). Workplace Essential Skills: Resources Related to the SCANS Competencies and Foundational Skills. Iowa City, Iowa. Retrieved from http://wdr.doleta.gov/opr/fulltext/00-wes.pdf

Wimmer, G., Myers, C., Porter, H., \& Shaw, M. (2012). Learning vicariously: Students' reflections of the leadership lessons portrayed in the office. Journal ofLeadership Education, 11(2), 52-71. doi: 10.12806/V11/I2/RF.

\section{Author Biographies}

Kellie Strawn served as the director of the College of Agricultural Sciences Leadership Academy at Oregon State University (OSU) from 2011 to 2015. During that time, Kellie was also involved in teaching and course development within the Department of Agricultural Education and Agricultural Sciences at OSU. Kellie's research interests include understanding the role of communication in leadership education.Email: kellie.strawn@oregonstate.edu

Aaron J. McKim is an Assistant Professor in the Department of Community Sustainability at Michigan State University. Aaron teaches courses in agriculture, food, and natural resources education, community sustainability, and leadership. Aaron's research interests include exploring educational approaches to develop the human potential to identify and implement sustainable solutions to ecological and social challenges. Email: amckim@msu.edu

Jonathan J. Velez, PhD, is an Associate Professor of Agricultural Education and Leadership at Oregon State University (OSU). Jonathan currently holds the Bradshaw Agricultural Sciences Leadership Education endowment and oversees the OSU Leadership Minor. Jonathan teaches both graduate and undergraduate leadership courses and his research interests include motivation, teaching methods, leadership development, and effective methods of leadership assessment. Email: jonathan.velez@oregonstate.edu 